\title{
Awareness and concern towards anesthesia among patients undergoing surgical procedure: A cross-sectional study at pre-anesthetic clinic of a Teaching Hospital
}

\author{
Mokłan SL', Shrestha U', Sharma $\mathrm{M}^{2}$, Karki M³ \\ 'Sushila Lama Moktan, ' 'Ujma Shrestha, Lecturers; ${ }^{2}$ Mona Sharma, Assistant Professor; ${ }^{3}$ Manan Karki, Consultant; Department \\ of Anesthesiology and Intensive Care, Kathmandu Medical College Teaching Hospital, Kathmandu, Nepal.
}

\begin{abstract}
Background: With the advent of anesthesia, surgery is no longer a race against the clock and surgeons. Many studies in the past have demonstrated limited knowledge among patients about various aspects of anesthesia.

Objectives: To assess the awareness and concern of elective surgical patients towards anesthesia.

Methodology: A cross-sectional questionnaire survey was conducted over two months' period in adult patients of age eighteen years and above. Two hundred surgical patients accessing services at the pre-anesthesia check-up clinic were interviewed using 12 questions assessing demographic characteristics, educational status and their knowledge about anesthesia.

Results: Out of 200 patients, only $32 \%$ knew that anesthesiologists provide anesthesia. It was found that $63 \%$ did not have any knowledge about the types of anesthesia. The most common fear among the participants about anesthesia was the fear of pain during surgery.

Conclusion: The study showed poor knowledge of patients regarding anesthesia.
\end{abstract}

Key words: Anesthesia; Awareness; Concern; Knowledge; Nepal

DOI: https://doi.org/10.3126/jkmc.v8i2.28168

\section{INTRODUCTION}

A nesthesia has played an integral role in medicine since the first successful surgical procedure that was performed under anesthesia in 1846 AD. Anesthesia is a foremost supportive specialty which allows major advanced surgeries to be performed but the general public does not have the usual perception regarding it as they have of other medical and surgical specialties. The public knowledge in this domain is still scarce despite the recent astonishing growth'. Various studies regarding the knowledge and attitude of the patients towards anesthesia has opined that it is very narrow, which is also observed in other medical and paramedical healthcare providers ${ }^{2,3}$.

\section{Address for correspondence}

\section{Dr. Sushila Lama Moktan}

Lecturer, Department of Anesthesiology and Intensive Care Kathmandu Medical College Teaching Hospital, Kathmandu E-mail: moktansushi@gmail.com
Unlike in developed countries, our part of world has always been in a low appraisal among the general population though anesthesia is a highly skilled profession. So, this can put on the fear and anxiety to patients undergoing surgery ${ }^{4}$.

Most patients scheduled for surgery do not know what to expect and often have limited knowledge of anesthesia. Patients have not been surveyed on their perception of anesthesia and the role of anesthetists in our hospital. Therefore, the main objective was to study patients' knowledge about anesthesia, anesthetists and their concerns. The secondary objective was to study the correlation between level of education and past anesthetic experience with their awareness relating to types of anesthesia.

\section{METHODOLOGY}

Following approval by Institutional Review Committee of Kathmandu Medical College, a cross-sectional predesigned questionnaire survey was conducted among 
200 consenting adult patients. The patients scheduled for elective surgery under different specialties who came to the Pre-anesthetic checkup (PAC) clinic between January and February 2018 were included. Patients who refused to participate or unable to consent (unconscious or critically ill patients, severe psychiatric illness) and those who were hard of hearing or unable to speak were excluded.

Patients aged 18 to 75 years of both gender were asked the questionnaire before pre-anesthetic assessment. A face to face interview was conducted based on responses to 12 questions structured to assess the patients' knowledge, perception and fear related to anesthesia. These open-ended interviews were carried out by a trained team of selected anesthesiologists who asked the questions in a similar manner to all the patients. The questionnaire consisted of a general part with questions on demography and the other section which had multiple choice questions with options covering discrete facts and sometimes requiring a "Yes", "No" or "Don't know" response.

Baseline demographic characteristics including age, gender, education and the referral faculty was recorded. The maximum level of education attained by participants was used to determine the educational status and was categorized as: patients with no formal education and those who could not to read or write as illiterate, patients with no formal education but could read or write as literate, those who had completed up to junior secondary level as SEE/SLC (Secondary education examination/School leaving certificate), high school (HS), bachelor and master degrees. This study hypothesized that the knowledge of patients on the entire scope of the roles of anesthetists and knowledge about types of anesthesia was associated with the educational status or previous exposure to surgery/anesthesia.

The collected data was entered and analyzed using Statistical Program for Social Sciences (SPSS) Version 22. Chi-square test was used to find the association among variables. A p-value of $<0.05$ was considered as statistically significant result.

\section{RESULTS}

Out of 200 patients, 82 were male and 118 were female. From the department of surgery, 56\% patients were referred whereas $20.5 \%$ from obstetrics and gynecology and $18 \%$ from Ear, nose and throat department. Educational status of patients is depicted in table 1. It was found that $21 \%$ of patients were literate whereas 19\% were illiterate.

Regarding the past surgical history, $45 \%$ of patients had undergone surgery in the past and the same percentage was anesthetized in the previous surgeries. The types of anesthesia received by patients in past surgeries are shown in figure below (Figure 1)

Out of the $45 \%$ patients anesthetized in previous surgeries, $10 \%$ could not remember the type of anesthesia they were provided while among the remaining patients, $46 \%$ had received general anesthesia, $24.4 \%$ had received spinal anesthesia and the rest had received the combination of the anesthetic techniques.

In regards to anesthetic techniques, the knowledge of patients about the types of anesthesia is presented in following table (Table 2). On interviewing about the various types of anesthesia they are familiar with, $63 \%$ of the patients didn't know about it at all. On questioning whether anesthesia is necessary for surgery or not, $5 \%$ of the patient gave negative response, $25 \%$ responded that they don't know whether it is necessary or not and $70 \%$ said that it is necessary.

Regarding the patients' knowledge towards the role of anesthesiologists following table (table 3) shows the response about the anesthesia provider. About one third of the patients (33.50\%) didn't know about the anesthesia provider.

In relation to Patients' knowledge about anesthesia, table 4 given below provides the response to the question about the effects of co-existing disease like Diabetes, Hypertension, Asthma, Epilepsy, Liver dysfunction, if smoker or an alcoholic on anesthesia.

Concerning whether the patient will be anesthetized during this surgery or not, $14.5 \%$ said that they don't know while $84.5 \%$ said "yes" they will be anesthetized. Patient's concerns regarding the anesthesia was assessed by a multiple response question (table 5). On questioning about the concerns of anesthesia, 42.5\% were concerned about pain during surgery where as $30.5 \%$ of the patients said they had no concern.

Table 6 given below shows whether the patients knew any role of anesthesiologists post-operatively or not. The anesthesiologists' role in the post-operative period was unknown to $59 \%$ of the patients. 


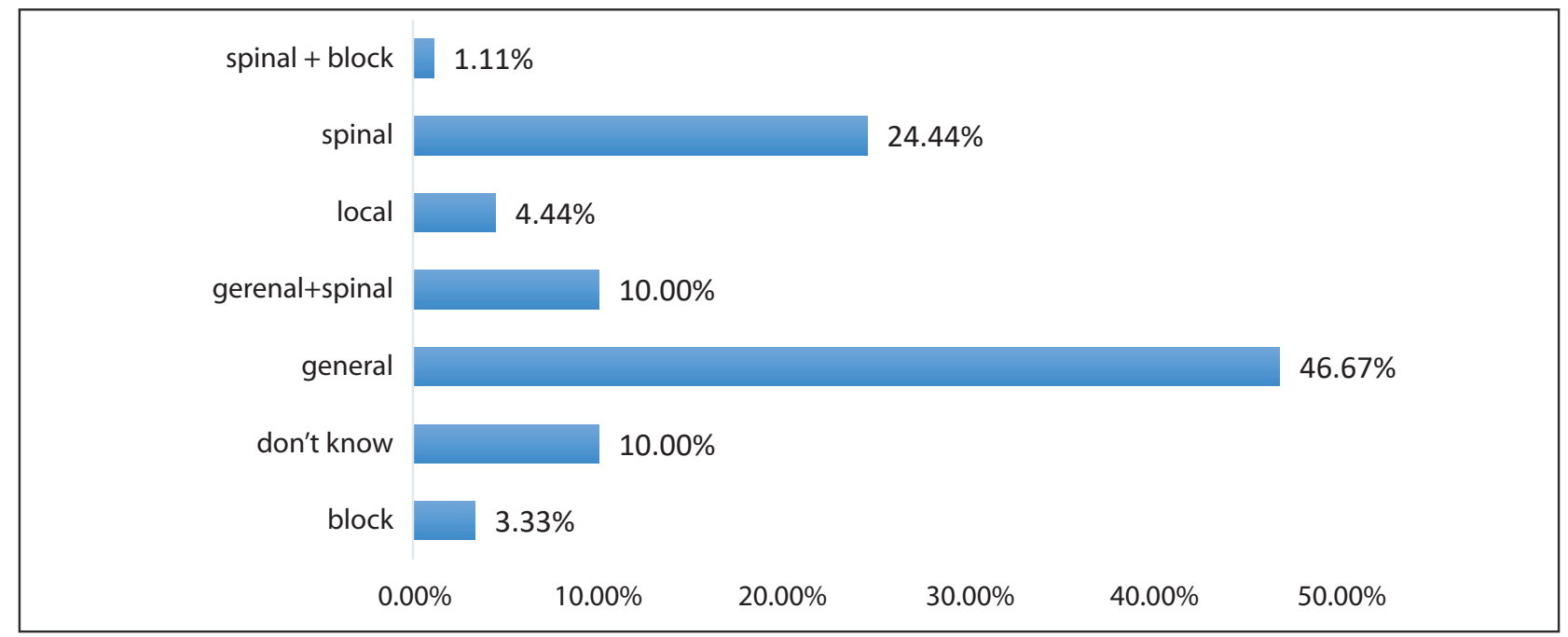

Figure 1: Types of anesthesia patient received in the past (multiple responses)

\section{Table 1: Educational status of the patients}

\begin{tabular}{lc}
\hline Variable & Frequency (\%) \\
Illiterate & $38(19 \%)$ \\
Literate & $43(21 \%)$ \\
SEE/SLC & $41(20 \%)$ \\
HS & $34(17 \%)$ \\
Bachelor degree & $30(15 \%)$ \\
Master degree & $14(7 \%)$ \\
\hline
\end{tabular}

Table 2: Knowledge about the types of anesthesia (multiple responses)

\begin{tabular}{lc}
\hline Variables & Frequency (\%) \\
\hline Don't know & $126(63 \%)$ \\
\hline General anesthesia & $60(30 \%)$ \\
\hline Regional anesthesia & $37(18.5 \%)$ \\
\hline Local anesthesia & $12(6 \%)$ \\
All & $2(1 \%)$ \\
\hline
\end{tabular}

Table 3: Knowledge about the anesthesia provider

\begin{tabular}{lc}
\hline Anesthesia provider & Frequency (\%) \\
\hline Anesthesiologists & $64(32 \%)$ \\
\hline Doctor & $14(7 \%)$ \\
Nurse & $25(12.50 \%)$ \\
Surgeon & $30(15 \%)$ \\
Don't know & $67(33.50 \%)$ \\
\hline
\end{tabular}

\section{DISCUSSION}

Kathmandu Medical College Teaching Hospital (KMCTH) being a tertiary referral center, Department of Anesthesia delivers over 5,000 anesthetics annually and runs a preanesthetic clinic six days a week with nearly three to four

\section{Table 4: Co-existing diseases and risks during} anesthesia

\begin{tabular}{lc}
\hline Risk during anesthesia & Response (\%) \\
\hline Don't know & $100(50 \%)$ \\
\hline No & $39(19.50 \%)$ \\
\hline Yes & $61(30.50 \%)$ \\
\hline
\end{tabular}

Table 5: Responses to the patients concerns about anesthesia

\begin{tabular}{lc}
\hline Concerns & Frequency $\%$ \\
\hline Pain during surgery & $85(42.5 \%)$ \\
\hline Pain after surgery & $13(6.5 \%)$ \\
\hline Needle prick & $23(11.5 \%)$ \\
\hline Not coming out of anesthesia & $32(16 \%)$ \\
\hline Backache & $21(10.5 \%)$ \\
\hline Awareness during anesthesia & $3(1.5 \%)$ \\
\hline Death & $9(4.5 \%)$ \\
\hline No concern & $61(30.5 \%)$ \\
\hline
\end{tabular}

Table 6: Awareness on role of anesthesiologists postoperatively

\begin{tabular}{lc}
\hline Variable & Frequency (\%) \\
\hline Don't know & $118(59 \%)$ \\
\hline Yes & $49(24.5 \%)$ \\
\hline No & $33(16.5 \%$ \\
\hline
\end{tabular}

hundred patients attending the pre-anesthetic clinic a month.

In this study, patients' awareness about anesthesia was not satisfactory. As a key supportive specialty, 
anesthesia allows major advanced surgeries but as compared to other medical and surgical specialties, the general population does not have adequate knowledge and perception towards anesthesia 5 .

Educational status was one of the factors found to significantly impact the knowledge about the type of anesthesia in this study; with increasing educational level, knowledge about the types of anesthesia increasing significantly. In the study by Jatharet et al, educational status and knowledge level was found to be directly proportional and knowledge level had been established higher in educated people ${ }^{2}$. They found that the patients who had higher educational status wanted to spend more effort to get accurate information and were more curious about anesthesia and operation experience. This may be attributed to the fact that increasing educational status increases the likelihood of being exposed to and informed about a wider range of subject areas.

In contrast to the findings of this study, in the study by Shevde K et al, there was no relation between anesthesia knowledge and educational level ${ }^{6}$. Since in this study, it was found that educational status has statistically significant effect on the knowledge about the type of anesthesia $(p<0.05)$ but as the number of patient was low in educated group, it is obvious that general population has to be more educated about anesthesia.

Statistically significant co-relation was found between the past exposure to anesthesia and the awareness about types of anesthesia. Likewise various studies have stated that patients who had previous experience of anesthesia were more aware about anesthesia techniques as compared to those who had no exposure ${ }^{7,8}$. In contradiction, it was said that neither anesthesia experience nor the anesthesia technique which was used before influence patients' knowledge and fears about anesthesia ${ }^{9-11}$. Since the questions they asked were about the overall knowledge about anesthesia which was not significant with the past exposure to anesthesia but in this study, the correlation between the past exposure and knowledge about the types of anesthesia was significant.

The most common concerns among the participants about anesthesia was the fear of pain during surgery (42\%) which is similar to the study by Kharaet al. $(28 \%)^{12}$. Other concerns were, not coming out of anesthesia, needle prick, awaken during surgery, backache, pain after surgery to even death. 'Not waking up' after anesthesia was the most common fear of patients regarding anesthesia reported in many studies. Post- operative pain was the next common fear which was expressed by patients across the world ${ }^{13-15}$.

Our study revealed that only $32 \%$ knew that anesthesia is provided by the anesthesiologist whereas 33.5\% didn't know about it at all and the remaining said that it is provided by nurse, surgeon or simply the doctor similar to the study by Irfan Ali et al. where only $42 \%$ knew that anesthesiologist is the one who gives anesthesia ${ }^{8}$. The reasons may be, first and foremost the patients primarily consult a surgeon for their ailment who may then refer the patients to an anesthesiologist, although not invariably. Also, anesthetists spend relatively shorter duration of contact with a conscious patient compared with other clinical medical specialists. It is therefore not surprising that they are regarded by some as 'unseen doctors ${ }^{16}$.

As majority of the patients had co-existing diseases like hypertension, diabetes, chronic obstructive pulmonary diseases, thyroid disorders, asthma which affect anesthesia and patient outcome. In this study, 50\% of the patients didn't know about the peri-operative effects of co-existing diseases. Only 30\% agreed that it does affect the outcome.

In most countries, patients generally have meagre awareness regarding the functions or role of anesthetists. Patients' knowledge of the diverse roles of anesthetists, especially those beyond the confines of the operating theatres, is very poor worldwide ${ }^{17,18}$. Fifty nine percent of the patients were not aware about the role of anesthetists' in post-operative management.

This study endures few limitations that includes population and information biases. The sample population in this study may not be truly representative of the rest of our country so, may not be accurate in generalizing the interpretations. The hospital attracts people from various socio-economic strata and the educational qualifications of the sample population varied widely in this study, but living in an urban environment and exposure to media may have influenced their answers. On the other hand, this study has recognized a few key issues which need to be addressed. Society of anesthesiologists has a very important responsibility to educate the patients and make them aware about the role of anesthesia and anesthesiologists, types, techniques and benefits of different procedures. This could come route in improving the image of anesthesiologist with the patients and the public as well. 
Though the interviews were conducted prior to assessment and receiving information from the anesthetists at the pre-anesthesia clinic, some patients may have had some information from surgeons or through previous encounters with anesthetists. The assessment was conducted to determine the anesthetist's role as perceived by surgical patients. Patients' awareness about the role of anesthetists in resuscitation, intensive care, acute and chronic pain management remains undetermined, and further studies are required to evaluate patients' knowledge in this regard.

\section{REFERENCES}

1. Lau L, Jan G, Chan TF. Preparation of patients for anaesthesia-achieving quality care.Hong Kong Med J.2002 Apr; 8(2):99-105. [DOI]

2. Jathar D, Shinde VS, Patel RD, Naik LD. A study of patients' perception about the knowledge of anaesthesia and anaesthesiologist. Indian J Anaesth. 2002 Feb; 46(1):26-30. [FullText]

3. Gurunathan $U$, Jacob R. The public's perception of anaesthesiologists- Indian attitudes. Indian J Anaesth. 2004 Dec; 48(6): 456-60. [FullText]

4. Cohen B, Ogorek D, Oifa S, Cattan A, Matot I. Smart marketing may improve public understanding of anesthesia profession. Israel journal of health policy research. 2015 Jun; 4:16. [PubMed]

5. Harms C, Young JR, Amsler F, Zettler C, Scheidegger D, Kindler CH. Improving anesthetists' communication skills. Anaesthesia. 2004 Feb; 59(2): 166-172. [PubMed]

6. Shevde K, Panagopoulos G. Survey of 800 patients' knowledge, attitudes, and concern regarding anaesthesia. Anesth Analg. 1991 Aug; 73(2): 190-8. [PubMed]

7. Sagün A, Birbicer H, Yapici G. Patients, who applied to the anesthesia clinic, perceptions and knowledge about anesthesia in Turkiye. Saudi J Anaesth. 2013 Apr-Jun; 7(2): 170-4. [DOI]

8. Kadri IA, Haider G, Memon I, Memon W. Awareness of patients regarding anesthesia; attitude towards basic types of anesthesia techniques. The Professional Med J. 2014 Oct; 21(4): 782-7. [FullText]

9. Osinaike BB, Dairo MD, Oyebamiji EO, Odesanya JO, Tanimowo A. Attitude of general public to risks associated with anaesthesia. East Afr J Public Health. 2007 Apr; 4(1): 40-2. [PubMed]

10. Van Wijk MG, Smalhout B. A postoperative analysis of the patient's view of anesthesia in a Netherlands'

\section{CONCLUSION}

The results of this study showed poor knowledge about anesthesia. Considerable numbers of patients were not aware about the types, role of anesthesia and anesthesiologists despite the fact that most of them had previous surgery. The major concern of the patients was pain during surgery. This could be attributed to their lower level of knowledge about anesthesiology subject as a whole.

teaching hospital. Anaesthesia.1990 Aug; 45(8):67982. [PubMed]

11. Lonsdale $M$, Hutchison GL. Patient's desire for information about anaesthesia. Scottish and Canadian attitudes. Anaesthesia. 1991 May; 46(5): 410-2. [PubMed]

12. Khara BN, Rupera KB, Gondalia KR, Kamat HV. Knowledge about anesthesia and perception about anesthesiologists among patients at a rural tertiary care hospital: A cross sectional survey. National Journal of Medical Research. 2013 Oct; 3(4):371-3. [DOI]

13. Hariharan S. Knowledge and attitudes of patients towards anesthesia and anaesthesiologists. A review. Anesten México. 2009 Sep; 21(3):174-8. [DOI]

14. Chew ST, Tan T, Tan SS, Ip-Yam PC. A survey of patents' knowledge of anaesthesia and perioperative care. Singapore Med J. 1998 Sep; 39(9):399-402. [PubMed]

15. Huang $Y$, Yang $K$, Ren $H$, Luo A. A survey of elective surgical patients' attitudes toward anesthesia in PUMC hospital. Chin Med Sci J. 2002 Jun; 17(2):7780. [PubMed]

16. Hume MA, Kennedy B, Asbury AJ. Patient knowledge of anaesthesia and peri-operative care. Anaesthesia. 1994 Aug; 49(8):715-8. [PubMed]

17. Djagbletey $R$, Aryee G, Essuman R, Ganu V, Darkwa EO, Owoo $C$ et.al.Patients' knowledge and perception of anaesthesia and the anaesthetist at a tertiary health care facility in Ghana. Southern African Journal of Anaesthesiaand Analgesia. 2017; 23(1):11-6. [DOI]

18. Hariharan S, Merritt-Charles L, Chen D. Patient perception of the role of anesthesiologists: a perspective from the Caribbean. J Clin Anesth. 2006 Nov; 18(7):504-9. [PubMed] 